\title{
OTRAS FORMAS DE INMIGRACIÓN EN LA NOVELA COSTARRICENSE CONTEMPORÁNEA: RIMA DE VALLBONA Y VIRGILIO MORA
}

\author{
Jorge Chen Sham
}

\begin{abstract}
RESUMEN
El artículo plantea la repercusión de la inmigración en términos de las percepciones/representaciones del espacio que debe ahora reconstruir el que emigra, pues ha dejado su casa y su comunidad, las cuales le proporcionaban su identidad y su pertenencia. La inmigración descentra al individuo y hace que se enfrente a un exilio ontológico y cultural, cuando esta se realiza por otras razones que las eminentemente económicas. Las dos novelas costarricenses en estudio, Mundo, demonio y mujer (Rima de Vallbona, 1991) y Memorias de un psiquiatra (Virgilio Mora, 2005), nos permitirán analizar otras formas de inmigración, respectivamente, por causa del reagrupamiento del núcleo familiar o especialización de estudios. Estas dos formas están ligadas a ese exilio que carcome y marca a los inmigrantes.

Palabras clave: inmigración, exilio, novela costarricense, Rima de Vallbona, Virgilio Mora.
\end{abstract}

\begin{abstract}
The article discusses the repercussions of immigration in terms of the perceptions and or representations of the space that the immigrants must now reconstruct after having left the home and community which provided to them their identity and relevancy. Immigration puts off center the individual and makes him or her confront an ontological and cultural exile, when immigration occurs for reasons other than economic ones. The two Costa Rican novels in this study, World, Demon and Woman (Rhyme of Vallbona, 1991) and Memories of a Psychiatrist (Virgilio Mora, 2005), allow us to analyze other forms of immigration, respectively, because of the regrouping of the familiar nucleus or specialization of studies. These two forms are bound to that exile in such a way that it preoccupies and marks the immigrants.
\end{abstract}

Key words: immigration, exile, Costa Rican novels, Rhyme of Vallbona, Virgilio Mora.

Dr. Jorge Chen Sham. Profesor de la Escuela de Filología, Lingüística y Literatura, Universidad de Costa Rica. Correo electrónico: jorgechsh@yahoo.com

Recepción: 11-12-09

Aceptación: 22-01-10 
Quisiera en primer lugar poner en discusión el viaje que significa la inmigración dentro de la imaginación diaspórica, pues al concebir esa facultad de contar desde lejos (Jiménez 2001: 28) y de narrar esta experiencia de quien debe salir de su propia tierra (patria), la inmigración supone: a) emprender el movimiento hacia un espacio extraño que acogerá al individuo con más o menos incovenientes; b) plantear la exotopía gracias a la cual el individuo debe dejar lo propio para enfrentarse a algo nuevo e inédito para él con sus repercusiones a un nivel de sus referencias identitarias; c) construir de nuevo su pertenencia cultural, ya que la significación del espacio está ligada a un sentido del lugar y a valores afectivos del sistema de organización en el que debe ahora insertarse el inmigrante.

Se trata, como se desprende de lo anterior, de plantear la repercusión de la inmigración en términos de las percepciones/representaciones del espacio: "L'idée du chez soi, du foyer, de la maison, mais aussi celle de la petite communauté, du groupe social sont matérialisées par toute une série de symboles qui donnent à l'espace une partie de sa lisibilité" (Fischer 1981: 15/ la cursiva es del autor). Si la inmigración en cuanto movimiento es un viaje a la alteridad y al descentramiento del individuo, ¿qué repercusiones posee el cambio de espacio en el individuo? El individuo valoriza lo propio y se siente atado. Esto quiere decir que estos factores de identidad se construyen en el ámbito de lo familiar y de lo que se siente como cercano, ¿qué le sucede al inmigrante, entonces, que debe insertarse en un nuevo ámbito extraño, ajeno, diferente? Un análisis de la inmigración tomará en cuenta, en efecto, este exilio en su doble categoría:

a) Un exilio psicológico, el cual implica una nostalgia hacia el país natal que se ha obligado a dejar no necesariamente por motivos político-económicos -aunque sea el más común y expandido- (Abellán 1987: 177).

b) Un exilio ontológico, que está relacionado con categorías culturales y se expresa bajo formas como la culpa de la expulsión edénica, el castigo divino del éxodo o la errancia, etc. $y$, en este sentido, obedece "no tanto [a] circunstancias exteriores como a la percepción por parte de un autor de su relación con la vida terrenal y el ser divino" (Bellver 1990: 165).

Para analizar la pertinencia de esta doble categoría del exilio en la inmigración, seleccionamos dos novelas costarricenses en las que el individuo debe salir de su propio país no tanto por motivos político-económicos. Es decir, hay otras formas de inmigración y es necesario que las planteemos todas, en un intento por ser exhaustivos y ver este fenómeno socio-cultural en todas sus dimensiones. En este sentido, si algo une desde un punto de vista biográfico a estos dos escritores costarricenses, es su decisión de vivir fuera de Costa Rica desde hace más de cincuenta años (Rima de Vallbona) o de cuarenta años (Virgilio Mora). Sus existencias los han conducido a reconstruir sus familias y sus vidas en los EE. UU., con lo cual su vivencia personal se trasluce de alguna manera en su escritura y en sus novelas.

Desde este punto de vista, María Amoretti subraya la condición de exiliada de Rima de Vallbona, quien se enfrenta en su proyecto literario a esa disyuntiva en la que el individuo migrante se siente marginado entre un aquí y un allá, entre lo nuevo y lo antiguo. De esta manera, este descentramiento conduce a que la escritura de Rima de Vallbona tenga la necesidad de "iniciar un proceso de crisis de identidad que obliga a un autoanálisis y a un examen de los contextos abandonados, impuestas por la distancia y por los traumas de la 
otredad experimentados en el nuevo contexto" (Amoretti 1989: 23) y los exponga en forma de un sentimiento de culpa. Lo mismo observó también Amoretti en la vida y en la obra de Virgilio Mora, a quien asoció con la causticidad de una pluma que denuncia y expurga desde su Nueva York a la sociedad costarricense con una visión muchas veces hiriente e irónica (1995: 7).

Vamos ahora a las novelas en estudio. Por ejemplo, en Mundo, demonio y mujer (1991), Rima de Vallbona nos propone el proceso autobiográfico de Renata, una mujer profesora de literatura en una universidad en Houston, quien está divorciada e intenta encontrar ese camino que oriente su existencia. Así, desde el punto de vista del personaje adulto y con una visión disfórica de la realidad actual, Renata emprende ese viaje a sus recuerdos de infancia y, para otorgarle mayor distancia al relato, un narrador heterodiegético introduce la narración en los que la focalización del personaje se dirige hacia el pasado y la distancia de su terruño latinoamericano:

\begin{abstract}
Allá, en el horizonte del trópico, tendido con languidez a lo largo de la línea que remata el mundo, majestuoso, sube el azul de las montañas a clavar en el cielo la punta de sus cumbres: ¡y esa atmósfera transparente y clara de las mañanas olorosas a calinguero, a frescor del rocío, a café recién chorreado, a mantequilla derrretida en el pan calentito que acaban de traer de la panadería, a tortillas que todavía humean en el comal! (16)
\end{abstract}

El acceso al arcano de la infancia se produce con unos motivos que hacen funcionar de inmediato nuestro imaginario cultural: el mítico paisaje azul y verdoso convoca las montañas para que del ascenso de la mirada, se descubra el espacio del "allá" y se palpe en perspectiva las cosas (Collot 1989: 155), tal y como le ocurre aquí a Renata en ese movimiento hacia la inmensidad de los cielos; pero ello la retrotrae a la infancia, segundo motivo, asociado aquí a olores y sabores que despiertan ahora sus sentidos. Queda claro que el "allá" se relaciona con ese terruño natal, mientras que el presente catapulta ese contraste que habla mucho del choque cultural de la latina Renata. Observamos entonces que las transformaciones diaspóricas generan, entonces, un proceso de descentramiento y la escritura autobiográfica, en tanto viaje y movimiento, se transforma en una metáfora del exilio de cuyo puerto de llegada aún no se tiene certeza. Por eso, la única verdad sostenible es la que confiesa Renata en su condición de exiliada frente a una existencia que no le depara ninguna luz a la salida de ese túnel:

\footnotetext{
El exilio es el portón negro que se cierra dejando atrás el ser de nuestro ser, despojo sin asidero ni salida a la luz. Todos estos años eternos, extraña a mí misma, entre rostros pálidorrubios y el verbo extranjero, me han enajenado. [...] Donde más perdida me siento en esta geografía anglosajona, es en la palabra, porque la palabra es la cosa misma que va delimitando minuto a minuto nuestro diario trajinar. (20)
}

La inmigración conduce, en la perspectiva de Renata, a un exilio que está marcado por la palabra "despojo" en su condición ontológica (se trata de la percepción de sí misma) y por el adjetivo "extraña a mí misma" en las relaciones intersubjetivas con el otro (se trata de la percepción de la diferencia identitaria). Para caracterizar a este otro, Renata utiliza dos expresiones inequívocas, "rostros pálidorrubios" y "verbo extranjero", con lo cual la distancia se expone en términos raciales y lingüísticos, aunque pesa más la segunda en la conciencia de Renata, pues se trata de esa colonización de la palabra a la que resiste la profesora y escritora latina. Ella reivindica su "palabra" como último resguardo de su identidad frente a la "geografía anglosajona" que la cerca en tierras houstonianas. Por ello, escribe y piensa en español; su resistencia radica en la seguridad de esa lengua que la ata con su pasado y su terruño, aunque otras muchas cosas hayan cambiado en su entorno y pueda establecer contrastes entre el Sur y el Norte, como expone a continuación: 


\begin{abstract}
Su pregunta acuciosa: ¿en qué se distingue ser diferente aquí, en el norte anglosajón, o allá, en el sur mestizo?; ¿entre los ensalzados rubiales de aquí y los despojados morenos de allá? Aquí o allá, es igual para mí, sigo enajenada; allá o aquí, el mismo exilio con hambre de eternidad. Allá o aquí, la angustia nos carcome por dentro, y por fuera nos va dejando descarnados y pálidos, fantasmas de nosotros mismos. Apátridas. Exiliados. Consumidos por la soledad. ¡Estemos donde estemos, siempre lo mismo! (21)
\end{abstract}

Vistas así las cosas, el Norte no se opone al Sur; el "aquí" y el "allá" tampoco lo son de una manera radical, por lo que Rima de Vallbona no se contenta con resolver la problemática del inmigrante en forma simplista: rechazo del país de llegada versus afirmación del lugar de nacimiento. Al plantearla la condición del inmigrante en términos de un exilio, ni el punto de llegada ni el punto de partida pueden ser ya ponderados positivamente, porque el que emigra ni es de "allá" ni es de "aquí". El proceso de descentramiento del inmigrante se vive como un verdadero "malestar cultural" (Villalobos 2000: 94) que plantea dudas e interrogantes sobre la biografía personal de Renata, al punto de que se instalan los sentimientos de desarraigo, de soledad y de vacío. Eso es lo que produce su situación de inmigrante en los EE. UU., un sentimiento de frustración que conduce al exilio ontológico del sujeto.

Pero, ¿por qué emigra Renata a los EE. UU.? Su inmigración no es forzada por lo económico; ella lo hace por matrimonio siguiendo a su marido Antonio, con el cual tendrá tres hijos, para luego dedicarse a la vida profesional de escritora y profesora universitaria. Lo que nos va contando Mundo, demonio y mujer, a partir de una historia fragmentaria en lo que concierne a su relación con Antonio, es la gran decepción sentimental que se opera en ella, cuando un día, una de sus amigas de su círculo houstoniano, hablando del feminismo y de los falsos ideales del matrimonio, comenta Faustina lo siguiente:

\footnotetext{
En nuestros tiempos era muy fácil confundir el amor con el deslumbramiento por todo aquello que la sociedad más exaltaba en el futuro marido y las conveniencias para asegurarse una holgura monetario que proveyera nuestros lujos y necesidades [...]. (33)
}

El ideal del marido perfecto se rompe, como le sucedió a Faustina con su marido, quien la engañó con su mejor amiga (31); así las cosas, las ilusiones y el idilio amoroso se quiebran haciendo que Faustina y Renata se interroguen sobre sus relaciones familiares, el sentido de sus vidas y, principalmente, del significado de una existencia ligada a un matrimonio infeliz, machista y cosificador. Veamos lo que le piensa Renata, cuando decide emprender un viaje a su terruño natal, lo que desde su propia valoración, se trata del rompimiento final y la toma de decisión de emprender un viaje, literal y metafórico, sin la compañía de Antonio:

\footnotetext{
(Nunca, ni de joven tuve para Antonio edad para hacer nada más que ser una mujer decente que honrara su casa, su nombre, su familia, sus hijos... toda la pasión que traje al matrimonio, la estrujó en un montoncito como un trapo viejo, desechable y me la arrinconó para siempre en el último recodo del alma... pero no murió nunca porque hay días que la siento rebullir y entonces me parece que la primavera vuelve a entrar por las galerías de mi ser...). (54, las cursivas son del texto)
}

Renata rompe las ataduras de la cárcel-matrimonio en la que ha estado por tanto tiempo recluida; sus trampas se desmoronan cuando advierte dos cosas: no solo ha vivido subordinada como pertenencia y patrimonio de su marido (de ahí el énfasis marcado del adjetivo posesivo "su"), sino también reprimida en sus ansias de vivir y de encontrarse a sí misma (para ello escoge el motivo de la "primavera"). Ahora emprende, ese tránsito hacia una existencia de la que no sabe con certeza qué le depara, aunque le da miedo la incertidumbre y la inseguridad de que debe de reconstruir sus afectos y su individualidad a un precio muy alto. Tal proceso es el que narra el resto de la novela, sin que haya un final conclusivo que cierre este proceso de una transformación definitiva de Renata. 
Por su parte, en Memorias de un psiquiatra (2005), Virgilio Mora nos propone una novela de un gran calado experimental en cuanto al manejo de la coordenada espacio-temporal. Si como dice Mijaíl Bajtín, la conciencia es la que permite integrar las diferentes líneas de lo vivido que se intersectan y se entrecruzan para darnos un punto de vista discriminador e integrador (1982: 133), la perspectiva diaspórica invade la narración autobiográfica para que tres personajes-actores (el mismo Mora en tres etapas del periplo fuera de su país) interactúen en una misma línea temporal. Las tres historias de los personajes corren paralelas para unirse en la más actual y de cobertura temporal más amplia. Hay una desconfianza, pues, en la linealidad del tiempo y de la Historia, por eso el dispositivo discursivo para atrapar el pasado es la memoria del recuerdo que funciona en forma no causal sino sorprendentemente relacional, como si fuera una "película muda" (523) que se va desenrollando y reproduciendo gráficamente en la conciencia del narrador. Así, la metáfora cinematográfica revela el mecanismo narrativo seleccionado para que funcione el proceso autobiográfico de Memorias de un psiquiatra, dentro de una integración cíclica que hace la instancia narrativa al final de la novela:

\footnotetext{
Con la aparición de Dorothy en escena, la película muda de los dos años en la ciudad de St. Louis, llega a su final, un final triste: la madre, tu esposa, con tres criaturas pequeñas, la menor en brazos, contempla primero, el desmoronamiento de su matrimonio, después, en una escena conmovedora, tu marcha, tu escapada, tu fuga hacia el oeste, the old west, la tierra de los pioneros, a empezar una nueva vida... a seguir la vida... (533)
}

Se trata de un resumen diegético que, en la contemplación conclusiva de la conciencia, despliega las escenas a 180 revoluciones, pasa a una velocidad increíble los condensados de una existencia que resaltan el itinerario de un viajero incansable por territorios de América del Norte (México y los EE. UU.-Missouri, California, Nueva York-) y nos prefiguran la función de un auténtico narrador-nauta por los territorios de la memoria y de la escritura, pues todo su trayecto biográfico se desarrolla en un instante recapitulador al estilo del aleph borgesiano en este cierre de la novela. Veamos, además, que este final de la novela involucra a las tres perspectivas pronominales (él/ yo/ tú) para que tengamos esa certeza de la conciencia integradora que guía en el decurso temporal y de la diégesis y que se cierra en la circularidad del tiempo según la última frase de la novela: "a empezar una nueva vida... a seguir la vida..." (533). La vida como la historia del personaje no han terminado, apenas comienza.

Ello no es inocente para el lector de Memorias de un psiquiatra, pues la novela se inicia precisamente, con esa decisión del personaje Mora, de dejar todo y de lanzarse al ruedo frenético de esos locos y desenfrenados años 60, tal y como comienza la novela, pues también cuando se emprende el viaje a EE. UU., este es el producto de una decisión "de empezar una nueva vida":

\footnotetext{
Llegó a California hacía año y medio. La enfermera de la que estaba enamorado lo acompañó en el viaje: tres días en su carro atravesando más de la mitad del territorio de los Estados Unidos, de St. Louis, Missouri, a Frisco en aquel Torino que él compró durante su internado, un carro nuevecito, flamante, en el que había penetrado a la enfermera la primera vez y después de muchas más, hasta que se cansaron los dos de andar fornicando por las calles: ella alquiló un apartamento; él dejó el suyo, a su esposa y a sus hijos: interno con un inglés rudimentario, estudiante de enfermería guapísima y muy joven, se pusieron a vivir juntos. (13)
}

A la luz del incipit de la novela, su final alcanza su inicio, de manera que desenlace y punto de partida se conectan en una suerte de relato que se va alargando en la medida en que se avanza en la película. La novela comienza ahí en donde termina, o más bien, se cierra ahí en donde todo se inicia: el matrimonio, los hijos, el abandono de la familia, el viaje californiano de alguien que quiere vivir el sexo, la droga y el rock and roll, tal y como 
nos enseñan múltiples canciones del periodo. Por otra parte, el protagonista se nos presenta como alguien que ha hecho su "internado" de psiquiatría en St. Louis y "con un inglés rudimentario", como alega en la presentación, lo cual subraya su condición de extranjero en tierras norteamericanas. Es más, al protagonista se nos presenta como un "residente latino" (14), pero que rápidamente cae en la cuenta de que Doris, la enfermera gringa, lo abandona para buscar otro amante. La perspectiva de la narración ahora cambia para que, en un pseudodiscurso psiquiátrico, Mora se confiese y nos haga un resumen del "teatro" (15) de su vida: estudios y privaciones en México, regreso a la patria, casamiento y nacimiento de los hijos e emigración a los EE. UU. para dejar atrás esa vida desenfrenada de aventuras sexuales que abochornaban a su familia en su natal Costa Rica:

\footnotetext{
¡Qué va, doctor! Apenas aprendí un poco de inglés, volví a lo mismo. Vine solo. Después me siguió ella. Estaba muy joven. No comprendí que la vida casera no se llevaba conmigo. Siempre tuve un poco de suerte con las mujeres. Las mujeres siempre han sido mi problema.
}

Usted no comprende, doctor. ¡El shock cultural! Desde que bajé del avión en St. Louis se dislocó mi sentido de la realidad. Antes: afásico con sólo cruzar el umbral de una puerta. Adentro del jet que me transportó de México a St. Louis nada más inglés, y yo boquiabierto sin entender nada, con muy poco dinero en el bolsillo, rumbo a un lugar del que no sabía nada, convencido de que con mi experiencia, mi título, todo iba a ir muy bien, iba a conseguir trabajo, un hospital, convencido el idiota de que me dejaban entrar a este país por mis méritos, mi diploma. Mentira, doctor, mentira. Carne de cañón, eso era yo. (15-16)

La cita es muy larga y no he podido cortarla por cuanto resume muy bien lo que esta experiencia de la inmigración hace descentrar y desubicar a los que se arriesgan a hacerlo. El "shock cultural" es la constatación contundente de quien puede analizar a la distancia su biografía personal; pero la palabra que mejor define lo que ello significa es el verbo que utiliza Mora en su confesión psiquiátrica: el verbo dislocar abiertamente nos plantea la problemática de las transformaciones diaspóricas de la inmigración; "dislocar" refuerza la idea de la separación, del movimiento abrupto, de la separación, del trastocamiento, que no sólo es físico sino mental en quien emigra. Y enfrentado a esa tierra de acogida, lo primero que se resalta es la incomprensión y la incapacidad lingüística, así como el derrumbamiento de las ilusiones y proyectos iniciales, los cuales chocan con la realidad y el tópico de "la tierra de promisión que es el Norte". Este es el choque del que nos habla Virgilio Mora, para contarnos su camino de aprendizaje y de aventuras. Observemos, además, que la emigración no se hace forzosamente por cuestiones económicas; Mora, con su diploma de médico, quiere hacer su vida profesional y buscar su éxito en los EE. UU. Para ello, tendrá que cambiar de especialidad al hacer su internado y residencia. Resumamos: busca el renombre de una carrera en los EE. UU., así como también huir de los líos de falda a los que se enfrentaba en Costa Rica. Esto último más bien se desata, al alejarse de su tímido y recatado país, y se enfrenta al sexo y a las drogas en una California que bulle y arde con el fin de desatarse de todas las prohibiciones conservadoras y católicas.

Por otra parte y volviendo a la cita que comentábamos anteriormente, las dos expresiones que utiliza Mora al final de ella no son nada inocentes. La primera es una afirmación con la que se desechan todas las ilusiones juveniles y los proyectos del inmigrante; la "mentira" que resulta cuando se compara las ilusiones y las propuestas iniciales con el resultado decepcionante de su desfase con sus contradicciones. La segunda expresión, "carne de cañón", se utiliza para designar a los soldados que van al campo de batalla; para Mora la inmigración cobra todo el sentido de una lucha y un combate para salir vivo y airoso, por lo 
que Memorias de un psiquiatra cobra la forma de una novela de aprendizaje y aventuras, en las que el choque cultural se manifiesta como una lucha cotidiana. Veamos otro fragmento de su confesión terapéutica:

\begin{abstract}
Mi batalla no fue en Vietnam. El ejército de este país nunca me reclutó. Suerte. Mi batalla cuerpo a cuerpo fue con la lengua, aprender a hablar, a leer, a escribir. Mi batalla fue con la discriminación, la desconfianza que se dibujaba en el rostro de la gente apenas el acento descubría mi origen; con la interminable espera, los largos meses que me tomó prepararme solo, rendir el examen que me permitía entrenar en un hospital [...]; mi lucha fue la de un hombre sin dinero, tratando de abrirse paso en un nueva cultura, atormentado todos los días y a todas horas por el fantasma de su conciencia, de sus sentimientos de culpa. (17)
\end{abstract}

Como en el caso de Rima de Vallbona, los grandes obstáculos de la inmigración a otro país se dibujan aquí; su punto central es el enfrentamiento a una lengua extraña y diferente, el inglés, que el inmigrante debe, por todos los medios, domar y dominar, con el fin de comunicarse; pero ahí viene el segundo obstáculo, el cual es enfrentarse a la indiferencia y a la discriminación, una vez que ya se puede expresar y hacerse comprender en una lengua que se habla con "acento". Para Mora, esta experiencia se interpreta con el término de "batalla"; su enfrentamiento es contra el mundo que lo rodea porque debe insertarse en él como un "soldado" que debe abrirse su lugar y buscar su posición en un campo minado y con muchos obstáculos. El choque cultural se dibuja con todos sus contornos para que, al final de la cita, se exprese lo que realmente motiva el malestar del protagonista. La culpa sale a relucir, pero esta no se encuentra en simples razones religiosas de transgresión moral ${ }^{1}$, sino en una que cala más hondo y que está en relación con su decisión de dejar su patria y de haber abandonado a su familia, cuando afirma que "todavía quisiera volver con mis hijos para poder dormir tranquilo, pero no puedo" (17). Es decir, la culpa tiene su origen en la separación familiar que realiza Mora cuando deja todo en St. Louis y, alocado y sin pensar en sus consecuencias, se deja arrastrar por las locuras y el sexo de los años 60; sin embargo, como vimos, no es la única.

De esta manera, Memorias de un psiquiatra se construye como un doloroso pero catártico proceso de la culpa, la cual sobreviene cuando se reconoce que se ha faltado a algún precepto o norma, o se ha actuado en contra de principios o valores codificados social o culturalmente como tales (Buber 1965: 127). Al respecto, Carlos Castilla del Pino identifica en la culpa un origen socio-genésico, pero su experiencia siempre es individual (1991: 55) y se manifiesta primeramente en el plano íntimo de la relación de ser humano consigo mismo para luego irradiar al plano de las relaciones interpersonales. Por otro lado, Castilla del Pino enfatiza que lo que podemos comprender e interpretar es la vivencia de la culpa (1991: 56) y, para captarla, debemos tomar en cuenta la imagen que los otros poseen del sujeto culpable, en la medida en que esta acción recae de alguna manera sobre estos también, pues [e]l objeto de la culpa afecta a la totalidad del hecho, es decir, a lo que se hace, a quién se hace, a cómo se hace, en dónde se hace, etc. El objeto de la culpa pasa de ser una acción a ser una situación (Castilla del Pino 1991: 99)

Se trata, a todas luces, de una imagen que el sujeto culpable ha interiorizado (la traición a sus padres y el haber abandonado a su primera esposa y a sus hijos -repitiendo la misma traición a su familia- y que se manifiesta, en el caso de Memorias de un psiquiatra, en esa insistencia de querer narrar su culpa y saldar las cuentas, como dice el propio Mora, con "el fantasma de su conciencia" (17). Con ello, Mora, el narrador, hace que la novela se transforme en la escritura de una "conciencia moral", que debe contar sus faltas y explicarlas 
para hacer, con el descargo de ellas, el lugar del encuentro consigo mismo, de su integración personal y social; prueba de ello son las tres narraciones que se desarrollan en la novela ${ }^{3}$ y que se condensan en una sola con esa valoración unitiva y recapitulativa de su cierre.

En conclusión, estas dos novelas costarricenses en las que sus personajes protagónicos, Renata (Mundo, demonio y mujer) o Mora (Memorias de un psiquiatra), se exponen en tanto exiliados en búsqueda de un sentido a sus existencias y se confiesan culpables en un proceso narrativo sin ambages ni tapujos, nos plantean que la inmigración es un fenómeno complejo y que no puede verse desde el punto de vista económico o de los derechos sociales y económicos del inmigrante, aunque constatamos su importancia y su defensa. En ambos casos estudiados, el exilio y la culpa surgen como categorías que explican con mayor pertinencia los avatares y las incertidumbres a los que se enfrenta el sujeto inmigrante, por lo cual su estudio y análisis amerita tener en consideración las implicaciones que tales experiencias dejan en la narrativa de Rima de Vallbona o de Virgilio Mora.

\section{Notas}

1. Más adelante, unas dos páginas se explica cuál sería la primera causa de este sentimiento de culpa; está en estrecha relación con los padres de Mora, sus esfuerzos por mandarlo a estudiar a México y darle la profesión de médico y la traición no dicha de casarse sin su consentimiento:

"Los pobres viejos, casi analfabetos, se habían sacrificado al infinito para tomar de la vida, con mi ayuda, lo que ésta jamás les había ofrecido. Así fue como me hice médico. La noche que salí de la casa de ellos a escondidas para casarme, les di con la puerta pesada de la realidad en las narices...

Tenía una inmensa deuda con ellos y mis padres más que nadie estaban convencidos de ello. Apenas se graduó el hijo se les fue con una extraña.

Nadie sabe para quién trabaja" (20).

2. Debería interpretarse esta novela de Mora desde planteamientos inversos, la desculpabilización y , por ende, el autoengaño en los que cae la conciencia moral para explicarse y hacer viable una autopercepción de sí mismo; pero ello se hace desde otra perspectiva que no es pertinente para nuestro trabajo. La referencia para esta interpretación sería el trabajo de Rafael Ángel Herra Autoengaño: Palabras para todos y sobre cada cual, San José: Editorial de la UCR, 2007.

3. Lamentablemente por razones de espacio no pudimos analizar las tres narraciones y sus contenidos diegéticos.

\section{Bibliografía}

Abellán, José Luis. 1987. "El exilio como categoría cultural: implicaciones filosóficas". Cuadernos Americanos 1 (1): 42-57.

Amoretti, María. 1989. "Rima de Vallbona: Entre la permanencia y el exilio". Revista de Filología y Lingüística 15 (2): 23-27.

1995. "El odioso de Mora”. Revista de Filología y Lingüística. 21 (2): 7-16. 
CHEN: Otras formas de inmigración en la novela costarricense contemporánea: Rima de Vallbona...

Bellver, Catherine. 1990. "Tres poetas desterradas y la morfología del exilio". Cuadernos Americanos 4 (19): 163-77.

Buber, Martin. 1965. The Knowledge of Man. London: Allen \& Unwin.

Castilla del Pino, Carlos. 1991. La culpa. (3 ${ }^{\text {a }}$. Reimpresión). Madrid: Alianza Editorial.

Collot, Michel. 1989. La poésie moderne et la structure d'horizon. París: Presses Universitaires de France.

Fischer, Gustavo-Nicholas. 1981. La psychosociologie de l'espace. París: Presses Universitaires de France.

Jiménez, Luis A. 2001. "Imaginación diaspórica: rescatando las impresiones sobre España de escritores románticos franceses”. Diáspora 11: 28-37.

Mora, Virgilio. 2005. Memorias de un psiquiatra. San José: Ediciones Perro Azul.

Vallbona, Rima de. 1991. Mundo, demonio y mujer. Houston: Arte Público Press.

Villalobos, Carlos. 2000. "La paradoja de la mujer escindida en la cuentística de Rima de Vallbona". Nuevos acercamientos a la obra de Rima de Vallbona (Actas del Simposiohomenaje). San José: University of Saint Thomas/ Editorial de la Universidad de Costa Rica: 93-104. 